\title{
RESEARCH
}

Open Access

\section{Spatio-temporal prevalence of malaria and anaemia in relation to agro-ecosystems in Mvomero district, Tanzania}

Susan F. Rumisha ${ }^{1 *}\left(\mathbb{D}\right.$, Elizabeth H. Shayo ${ }^{1}$ and Leonard E. G. Mboera ${ }^{1,2}$

\begin{abstract}
Background: Agro-ecological systems have been associated with increased malaria intensity. This study determined association between different agro-ecological systems, prevalence of malaria parasitaemia and anaemia in Mvomero district, Tanzania.

Methods: The study was carried out in three agro-ecosystems namely, savannah, rice-irrigation, and sugarcane. Malaria and anaemia prevalence were measured in four seasons of a year. Villages were categorized according to environmental characteristics, proportion of water-shaded areas and agro-ecosystems. Mixed-effects logistic regression analysis was used to determine factors associated with malaria infection.

Results: A total of 7888 individuals were involved with the overall malaria prevalence of $34.4 \%$. Plasmodium falciparum was the dominant (99.52\%) malaria species. Malaria prevalence was highest (42.9\%) in children of 10-15 years of age, and significantly low during dry and hot season. Of the infected individuals, $78.1 \%$ were from rice-irrigation, 18.7\% savannah and 3.2\% sugarcane ecosystem. Individuals living in villages with high levels of water-shaded areas had highest malaria risk. Over three-quarters (78.9\%) of the individuals slept under a mosquito net, with the highest (88.5\%) coverage among individuals in sugarcane ecosystem. On average $47.1 \%$ of the children were anaemic. Anaemia was more prevalent (60.5\%) among individuals in the savannah than in the rice-irrigation (48.2\%) or sugarcane communities (23\%). Analysis indicated that ecosystems and levels of water-shaded area were highly correlated, and altered levels of malaria infection. Gender, age, mosquito net-use, and season were other significant determinants of $P$. falciparum infection. Males had higher odds than females $(\mathrm{OR}=1.16,95 \% \mathrm{Cl} 1.05,1.29)$. The risk for children $6-9$ years and older children (10-15 years) was over $50 \%$ and $24 \%$, respectively, higher compared to young ones ( $0-5$ years). Use of mosquito net reduced malaria risk by $26 \%$. The risk of infection was higher during dry and cool season (OR $=1.92$, $95 \% \mathrm{Cl} 1.66,2.23)$ compared to other seasons. Living in villages with high level of water-shaded areas increased the chances of getting malaria up to 15 times than living in drier areas. Similarly, infection odds increased when living in savannah and rice-irrigation ecosystems than in the sugarcane ecosystem.
\end{abstract}

Conclusions: Findings show significant variations in malaria prevalence between communities living in different agro-ecosystems within the same district. Local malaria control strategies should consider these variations and liaise with agricultural experts while designing interventions to maximize effectiveness.

Keywords: Malaria, Parasitaemia, Anaemia, Agro-ecosystems, Tanzania

\footnotetext{
*Correspondence: siaeli@gmail.com

${ }^{1}$ National Institute for Medical Research, 3 Barack Obama Drive, P.O.

Box 9653, Dar es Salaam, Tanzania

Full list of author information is available at the end of the article
} 


\section{Background}

Malaria remains a major public health problem in the tropic and sub-tropic regions, with approximately 216 million cases and half a million deaths reported annually $[1,2]$. About $90 \%$ of the malaria cases and deaths occur in Africa [1,3-6]. Tanzania stands among the top ten countries with high malaria transmission and population at risk in eastern and southern African region $[1,7,8]$. The disease is endemic in almost all parts of the country, with over $95 \%$ of the population at risk of infection. In Tanzania, malaria contributes to $26 \%$ of all outpatient attendances, resulting in an estimated 7.7 million confirmed and clinical malaria cases annually [7, 9]. The disease accounts for $33.4-42.1 \%$ of all hospital admissions and it is the leading cause of hospital deaths in Tanzania $[1,10]$. Malaria has also been confirmed to attribute to anaemia in children [11-13].

The prevalence and incidence of malaria vary from place to place and times of the year. Both climatic and non-climatic factors affect malaria transmission. Climatic factors, including temperature, rainfall and relative humidity, greatly influence the pattern and levels of malaria [14-18]. Non-climatic factors that influence malaria risk include types of vector, species of malaria parasite, host immunity, insecticide and drug resistance, environmental development and urbanization, population movements, and other socio-economic factors including livelihoods [19-30]. In sub-Saharan Africa, agricultural practices and other livelihoods activities have been described to have impact on malaria transmission [15-23], either through increasing mosquito reproduction and survival or exposure of humans to mosquito bites $[22,31]$. To maximize productivity, there had been intensification of food production methods, increased crop irrigation and forest-clearing, all of these contributed to an increase in mosquito breeding habitats [3234]. For instance, swampy rice cultivation methods and use of flooded paddies create favourable breeding sites for Anopheles gambiae which is the main malaria vector $[35,36]$, while agricultural activities in savannah areas favour Anopheles funestus [37]. Moreover, there are evidence that large-scale development projects contribute to increasing in malaria transmission intensities. These include the introduction of new agricultural practices, infrastructural development programmes, such as water resource management, road constructions and maintenance, brick making and mining [38-41].

Like in most African countries, over two-third of the population in Tanzania lives in rural areas, where majority are involved in agricultural activities $[9,42]$. Communities, depending on their locations and crops cultivated, opt for specific farming practices to optimize agricultural productivity $[43,44]$. These options alter risk of acquiring malaria infection and transmission intensities. Although the density of malaria vectors has been reported to vary among areas within small proximity but practicing different farming practices [34, 36, 45], a study in Kenya has shown low malaria prevalence in areas where irrigation is practised than in non-irrigation areas [32]. These multidirectional findings result into complexity when deciding on disease control and vector management strategies [22, 32]. To complement and sustain the gains achieved in malaria control, it is crucial that the farming communities and those making decisions in health and agricultural sectors understand the impact of various agricultural practices and agro-ecosystems on malaria transmission dynamics [46-48]. However, there are limited number of studies that have established the micro effect of choices on ecosystems and farming practices on malaria burden $[13,24,47,49-51]$. As a result, knowledge on their associations remain relatively weak. Such information is critical for evidence-based actions, to guide health policy and planning, such as promotion of intersectoral strategies in malaria control and developing area-specific communitytailored control strategies [52,53]. This study was carried out to determine the relationship between different agroecological systems and the prevalence of malaria and anaemia among rural communities in Mvomero district in east-central Tanzania.

\section{Methods \\ Study area}

This study was carried out in Mvomero district in eastcentral Tanzania. The district is located between latitudes $5-8^{\circ} \mathrm{S}$ and longitudes $37-39^{\circ} \mathrm{E}$, and lies on the foothills of Nguru Mountains to the north-west and Uluguru Mountains to the south-east. The area lies on the Wami River basin. Most of the inhabitants (80\%) earns their livelihoods from agriculture. The main economic activities include rice farming, sugarcane plantations and livestock production. Administratively the district is divided into four divisions, 30 wards and 101 villages. Total human population is estimated at 312, 109 with an average growth rate of 2.6\% [54]. Rainfall is high $(1146 \mathrm{~mm}$ per annum) and bimodal with a relatively short dry spell between June and September. The mean maximum temperature is $31{ }^{\circ} \mathrm{C}$ (October to March); whereas the mean minimum temperature is $19^{\circ} \mathrm{C}$ (June to September).

Two divisions, namely Mvomero and Turiani, lying at 293-379 m above sea level were selected for the study. Within the division, seven villages (Luhindo, Dakawa, Dihombo, Mkindo, Mbogo, Komtonga and Mtibwa) characterized by three agro-ecosystems, savannah, riceirrigation and sugarcane plantation were included in the study (Fig. 1). The agro-ecosystems were grouped based on vegetation cover and main agricultural practices 


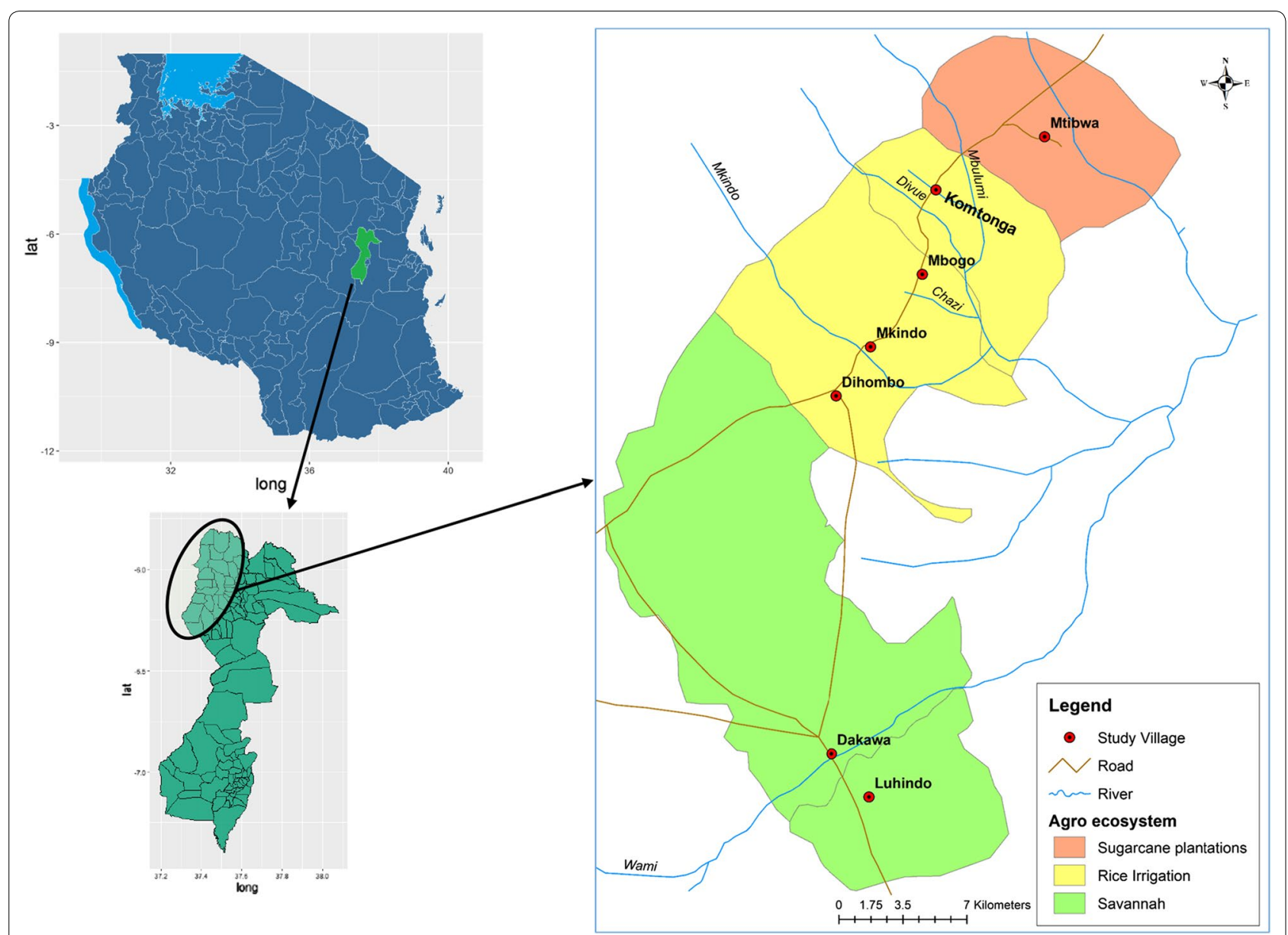

Fig. 1 Location of study villages with their agro-ecosystems in Mvomero district, Tanzania

performed by the community members in the respective villages. The total area covered by the study was approximately $20 \mathrm{~km} \times 60 \mathrm{~km}$. Other important water bodies existing within these villages include four rivers i.e. Wami, Mkindo, Mbulumi and Divue. These rivers are the main sources of water for irrigation (Fig. 1).

\section{Study design}

This was a cross-sectional survey conducted in 4 phases during four climatic seasons of August (dry and cool season) 2004, November 2004 (short rains), February 2005 (dry and hot season) and May 2005 (long rains) (Fig. 2). With assistance from village authorities, a specified number of households was selected randomly and the selected families were invited to participate in the study. The sampling frame was the updated household listing provided by the village leadership. Primary schools within selected villages were visited for convenience inclusion of schoolchildren in the study; each village had only one primary school. The minimum number of individuals required for the survey was estimated using a formula for calculating sample size for cross sectional prevalence studies $[55,56]$. A conservative malaria prevalence of $50 \%$ was considered [57] as precise estimates for the prevalence for Mvomero district was not available at times when the study was designed. With a margin error of 5\% and 95\% confidence level $(\alpha=5 \%, Z=1.96)$, and a design effect of 1.5 to account for variation on prevalence between sites, a minimum sample size of 576 households was established to be sufficient for the study. A probability proportional to size (total number of households within a village) was used to obtain sample size for each village. On average, 2 to 4 participants (average of 3 ) were expected from each household, hence expected individuals to be included in each survey phase were estimated at 1728. A nonresponse rate of $10 \%$ was considered to give a minimum sample of 1900 per round of the survey. Community malaria prevalence and related parameters have been estimated using school children [41, 58-62] and it is convenient to study this group in terms of costs and logistics; with that, the sample size was split between community and schools into a ratio of 30\%:70\% for implementation. 


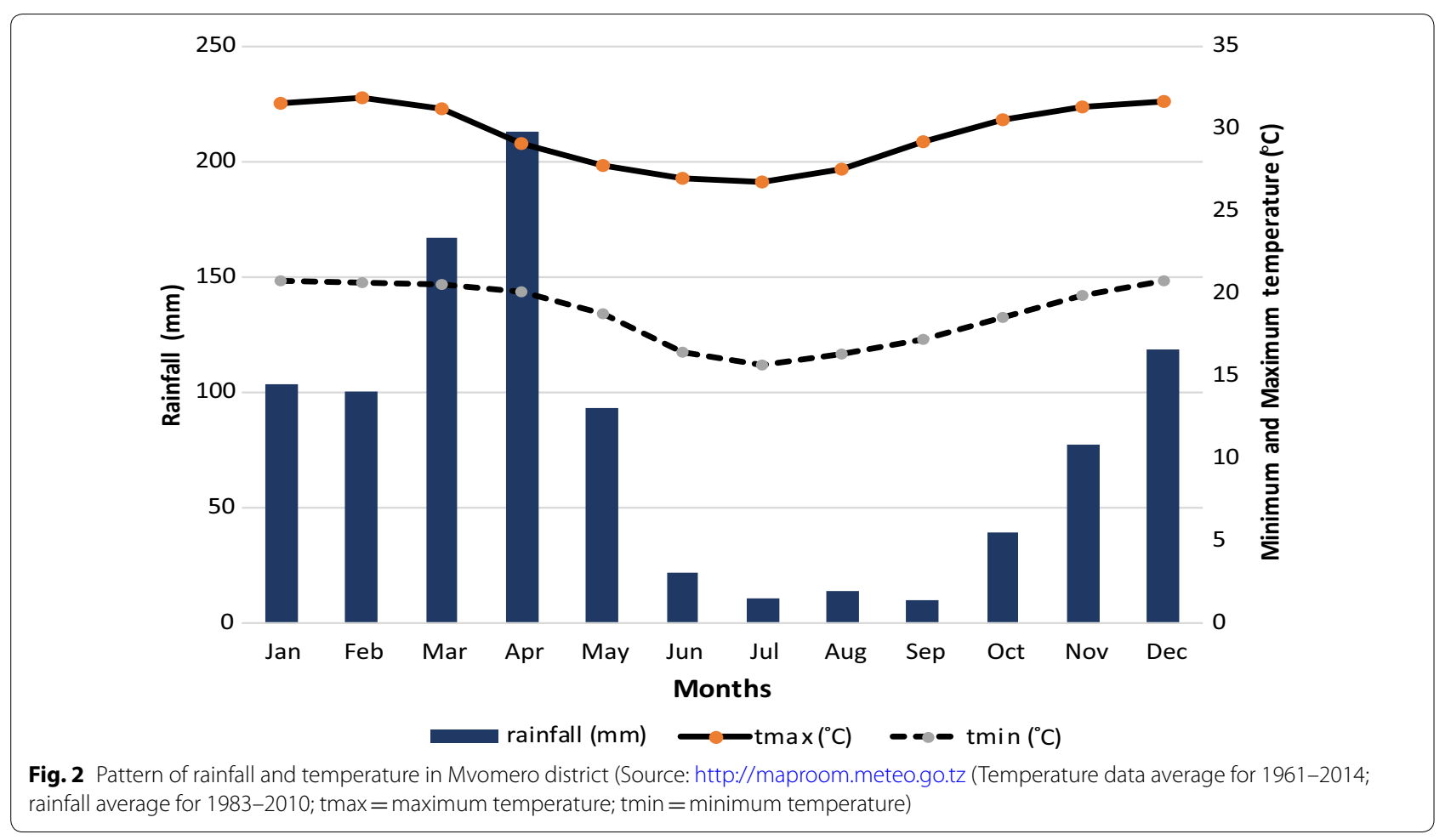

That was also supported by the fact that, if screening was to be done simultaneously at both sites at the same day, most children aged 6-15 years will be at school hence targeting schools as point of collection was convenient.

\section{Environment assessment and categorization of study sites}

Environment assessment survey was conducted in all seven villages. Departments of Land, Natural Resources and Agriculture were consulted and discussions were held. Physical visits and observations were made to the study villages. Information documented include land use and land cover patterns, i.e. farming systems (crop/ livestock production), infrastructure, natural resources, water sources and reservoir, ecosystems, water-shaded, type of houses, environmental cleanliness and weather patterns. Water-shaded area was defined as those reported to hold standing water continuously for 4 to 6 months a year. It is a proxy for surface water availability at micro-level-which is associated with providing conducive mosquito breeding sites. Results of the environmental assessment were used to stratify the study area into three agro-ecosystems; (i) savannah, including the villages of Luhindo and Dakawa; (ii) rice-irrigation which comprised Dihombo, Mkindo, Komtonga and Mbogo; and (iii) sugarcane plantations in Mtibwa village. Within the rice-irrigation ecosystem, flooding irrigation, which is a traditional method, was common practiced in Komtonga Dihombo and Mbogo. In this area, farmers use temporary made water canals to irrigate their rice fields, these are constructed each season based on how the paddies are needed. Mkindo village adopted a formal irrigation scheme system using wellconstructed canals. There is a main canal fed from the river (set by gravity) and local farmers are connected to irrigate their farms. The communities in savannah agro-ecosystem cultivates rice and maize, in addition, they are involved in livestock keeping. Dakawa village is characterised by large-scale rice farms with well-maintained water scheme. The main season for rice cultivation starts from late November to February (preparations and planting) to May-July (harvesting) and the off-season runs from June through December. Most farmers cultivate during the main season with a few doing both seasons $[13,33]$. The village authorities identified areas for cultivations where community members either buy and own the land or hire from the authorities on annual basis. The average farm size varies with the type of cropping system, hence varies from village to village and range from 2 to 3 ha. Farmers reported to walk a range of $1-3 \mathrm{~h}$ to their farms. Information on amount of permanent water bodies observed, type of vegetation and farming systems was used to categorize the villages into levels of water shaded areas. The list of villages in a decreasing order of water-shaded area is Komtonga, Mkindo, Mbogo (high level); Dihombo, Luhindo, Dakawa (medium to 
low level) and Mtibwa (dry land). The study area characteristics have been extensively described elsewhere $[34,51,63]$.

\section{Malariometric surveys}

Clinical examination and screening for malaria parasites for community members was done at a central point in respective villages. Primary schoolchildren were examined at their own schools under the supervision of school head teachers. In each school, approximately 200 (average per schools taken to reach the needed sample) children were examined for malaria parasites and about 15\% examined for haemoglobin levels. To get age representation, children were included from all seven classes with the needed sample equally split and balancing for gender groups. A systematic sampling procedure was applied to a class register (separately for boys and girls) to select children. All children below 15 years both in and out of school were examined for splenomegaly through the palpation of the spleen in a horizontal position by the research physician [64].

History of fever and malaria symptoms were recorded and an axillary temperature was measured with a digital thermometer. Thick and thin blood smears were collected and stained with Giemsa and examined with a binocular microscope with an oil immersion lens to quantify the parasitaemia. Parasitaemia was measured counting the number of asexual parasites against the number of leukocytes in the blood film, based on a putative count of 8000 leukocytes per microlitre. The number of asexual parasites was counted against 200 leukocytes using a hand tally counter. A slide was considered negative if no parasite were seen after scanning 200 fields. Children with positive test results were followed and treated following recommended treatment guidelines and referred to the nearest health facility when necessary. Each individual was asked on whether he/she slept under a mosquito net a night before the survey. Parents or caretakers were consulted to confirm information on use of mosquito net provided by very young children (between 3 and 5 years). Among the schoolchildren, pictures of mosquito nets (with different colours) were used to illustrate for those who had difficulties in understanding the question on net use.

\section{Data analysis}

The data were double-entered, cleaned and validated in Epi-Info 6.04 (CDC Atlanta, USA, 2001). Descriptive and statistical analysis were carried out in MS Excel and Stata 13 (StataCorp. 2013), respectively. Characteristics of the study participants were examined and presented. Mean with standard deviations and median values (with interquartile ranges, IQR) were calculated for continuous variables (where appropriate) while proportions were used for categorical variables. A binary variable describing malaria status was created to take value of 1 if malaria was present and 0 otherwise. Malaria prevalence levels were compared between different characteristics. An individual was considered to have fever if the body temperature was $\geq 37.5^{\circ} \mathrm{C}$. Normal haemoglobin level was taken when concentration was $\geq 11 \mathrm{~g} / \mathrm{dl}$ while a person with value less than $11 \mathrm{~g} / \mathrm{dl}$ was considered anaemic. Mild anaemia was defined if haemoglobin was $\geq 10-\leq 11 \mathrm{~g} / \mathrm{dl}$, moderate between $\geq 7$ and $<10 \mathrm{~g} / \mathrm{dl}$ and severe anaemia if haemoglobin was less than $7 \mathrm{~g} / \mathrm{dl}$ [7]. Two-sample test of proportions, $\chi^{2}$-test, Fisher's exact and $t$ test were used for comparison where appropriate. Cuzick's test of trend [65] was used to determine ordered effect of levels watershaded area on malaria prevalence. The statistical level of significance was set at $\mathrm{p}<0.05$.

A mixed-effects logistic regression model was used to determine association between malaria infection status and other factors including climate seasons, agro-ecosystems, levels of water-shaded area, use of mosquito net and demographic characteristics. The model includes village-specific random effects to account for clustering. Pearson's correlation coefficient was used to detect highly correlated covariates $(r>0.8)$. To select which covariates to retain between a correlated pair, the two were ranked based on their goodness of fit assessed through Akaike information criteria (AIC) [66] and pseudo- $\mathrm{R}^{2}$. The best fitting one was used in the final model. The smaller the $\mathrm{AIC}$ and the higher the pseudo- $\mathrm{R}^{2}$ indicated the better the variable. The Variance Inflation Factor (VIF) and Farrar-Glauber test (F-G test) for multicollinearity [67] were performed and variable with VIF $>4$ were omitted in the model. Odds ratios (with $95 \%$ confidence intervals) of all variables used in the final model are presented to indicate the strength and direction of the association.

\section{Ethical considerations}

Ethical clearance was sought from the Medical Research Coordinating Committee of the National Institute for Medical Research, in Tanzania (NIMR/HQ/R.8a/Vol IX/297). Permission to conduct the study was sought from Mvomero district authority. Oral informed consent was obtained from the community members $\geq 18$ years and assent was obtained from parents and teachers in the respective households or schools.

\section{Results}

\section{Malaria parasitaemia and splenomegaly}

A total of 7888 individuals were involved in the four cross-sectional malariometric surveys. Among these $52.1 \%$ were females, most (45.1\%) aged between 6 and 9 years and over three quarters (78.9\%) of respondents 
Table 1 Characteristics of study individuals by malaria infection status $(\mathrm{N}=\mathbf{7 8 8 8})$

\begin{tabular}{lcccc}
\hline Variable & $\begin{array}{l}\text { Negative } \\
\text { N (\%) }\end{array}$ & $\begin{array}{l}\text { Positive } \\
\mathbf{N}(\%)\end{array}$ & $\begin{array}{l}\text { Total } \\
\mathbf{N}(\%)\end{array}$ & p-value \\
\hline Gender $^{\mathrm{a}}$ & & & & \\
$\quad$ Female & $2781(53.8)$ & $1327(48.9)$ & $4108(52.1)$ & $<0.001$ \\
Male & $2389(46.2)$ & $1389(51.1)$ & $3778(47.9)$ & \\
Age category (years) & & & & \\
$0-5$ & $508(9.8)$ & $246(9.1)$ & $754(9.6)$ & $<0.001$ \\
$6-9$ & $2300(44.5)$ & $1258(46.3)$ & $3558(45.1)$ & \\
$10-15$ & $1377(26.6)$ & $1037(38.2)$ & $2414(30.6)$ & \\
$>15$ & $987(19.1)$ & $175(6.4)$ & $1162(14.7)$ & \\
Study subjects & & & & \\
Community members & $1723(33.3)$ & $492(18.1)$ & $2215(28.1)$ & $<0.001$ \\
Schoolchildren & $3449(66.7)$ & $2224(81.9)$ & $5673(71.9)$ & \\
Usage of mosquito net & & & & \\
No & $1005(19.4)$ & $663(24.4)$ & $1668(21.2)$ & $<0.001$ \\
Yes & $4167(80.6)$ & $2053(75.6)$ & $6220(78.9)$ & \\
\hline
\end{tabular}

a 2 individuals missing information on gender

reported use of mosquito net during the previous night (Table 1).

Overall malaria prevalence was $34.4 \%$ (2716/7888). It was similar among female and male individuals, apparently, the infection was concentrated in schoolchildren (p-value $<0.001$, Two-sample test of proportions). Children aged 6-9 years carried the most burden followed by those aged $10-15$ years. Malaria infection rate was higher among individuals not using nets than those reported to use $(39.7 \%$ vs. $33.0 \%$, p-value $<0.001)$. School-children $<5$ years reported higher net usage as compared to those of the same age from the community group $(89.2 \%$ vs. $82.3 \%$, p-value $=0.025)$. In contrary, individuals 10-19 years sampled from the community reported higher usage than those in sampled at their schools $(85.1 \%$ vs. $73.8 \%$, p-value $<0.001)$. Malaria parasite prevalence was highest (42.9\%) in the age group $10-15$ years and lowest among $>15$ years old $(15.1 \%)(<0.001)$. The prevalence levels in other age groups was $32.6 \%$ and $35.4 \%$ in $\leq 5$ years and $6-9$ years old, respectively. Prevalence within rounds were $36.7 \%(767 / 2088)$ round 1 , $38.2 \%(730 / 1913)$ round $2,26.6 \%(508 / 1913)$ round 3 and $36.0 \%(711 / 1974)$ during round 4.

Proportionally, less infected individuals were observed during round 3 (February 2005, dry and hot season) as compared to other periods ( $\mathrm{p}$-value $<0.0001$ ). Of the 2716 individuals with malaria parasites, 507 (18.7\%) were from savannah (Luhindo, Dakawa), 2122 (78.1\%) riceirrigation (Dihombo, Mkindo, Komtonga and Mbogo) and 87 (3.2\%) sugarcane ecosystem (Mtibwa). Significant differences ( $p$-value $<0.0001)$ in malaria prevalence were
Table 2 Distribution of malaria infection by study round $(R)$, village, ecosystem and watershed

\begin{tabular}{|c|c|c|c|c|}
\hline Variable & $\begin{array}{l}\text { Negative } \\
\mathrm{N}(\%)\end{array}$ & $\begin{array}{l}\text { Positive } \\
\text { N (\%) }\end{array}$ & $\begin{array}{l}\text { Total } \\
\mathrm{N}(\%)\end{array}$ & $p$-value ${ }^{a}$ \\
\hline \multicolumn{5}{|l|}{ Survey rounds (R) } \\
\hline $\begin{array}{l}\text { R1 (August: dry and } \\
\text { cool) }\end{array}$ & $1321(25.5)$ & $767(28.2)$ & $2088(26.5)$ & \multirow[t]{4}{*}{$<0.001$} \\
\hline $\begin{array}{l}\text { R2 (November: short } \\
\text { rains) }\end{array}$ & $1183(22.9)$ & $730(26.9)$ & $1913(24.3)$ & \\
\hline $\begin{array}{l}\text { R3 (February: dry } \\
\text { and hot) }\end{array}$ & $1405(27.2)$ & $508(18.7)$ & $1913(24.3)$ & \\
\hline R4 (May: long rains) & $1263(24.4)$ & $711(26.2)$ & $1974(25.0)$ & \\
\hline \multicolumn{5}{|l|}{ Village } \\
\hline Komtonga & $380(7.4)$ & $746(27.5)$ & $1126(14.3)$ & \multirow[t]{7}{*}{$<0.001$} \\
\hline Mkindo & $672(13)$ & $470(17.3)$ & $1142(14.5)$ & \\
\hline Mbogo & $655(12.7)$ & $557(20.5)$ & $1212(15.4)$ & \\
\hline Dihombo & $789(15.3)$ & $206(7.6)$ & 995 (12.6) & \\
\hline Luhindo & $776(15)$ & 349 (12.9) & $1125(14.3)$ & \\
\hline Dakawa & $786(15.2)$ & $301(11.1)$ & $1087(13.8)$ & \\
\hline Mtibwa & $1114(21.5)$ & $87(3.2)$ & $1201(15.2)$ & \\
\hline \multicolumn{5}{|l|}{ Ecosystem } \\
\hline Savannah & $1575(30.5)$ & $507(18.7)$ & $2082(26.4)$ & \multirow[t]{3}{*}{$<0.001$} \\
\hline Rice-irrigation & $2483(48)$ & $2122(78.1)$ & $4605(58.4)$ & \\
\hline Sugarcane & $1114(21.5)$ & 87 (3.2) & $1201(15.2)$ & \\
\hline \multicolumn{5}{|l|}{ Water shed area } \\
\hline High & $1707(33)$ & $1773(65.3)$ & $3480(44.1)$ & \multirow[t]{4}{*}{$<0.001$} \\
\hline Medium-Low & $2351(45.5)$ & $856(31.5)$ & $3207(40.7)$ & \\
\hline Dry & $1114(21.5)$ & $87(3.2)$ & $1201(15.2)$ & \\
\hline Total & 5172 (65.6) & 2716 (34.4) & 7888 & \\
\hline
\end{tabular}

a $p$-values estimated from Chi square test of association

observed between the three agro-ecosystems with individuals from the sugarcane ecosystem having the lowest rate (Table 2).

The highly water shaded areas indicated the highest prevalence. Trend across villages was positive and highly significant, with individuals in villages with high levels of water-shaded areas (Komtonga and Mkindo) having highest malaria risk (Cuzick's test, $\mathrm{p}$-value $<0.001$, Table 3, Fig. 3). The patterns by different age categories show a very similar trend.

The median body temperatures of the examined individuals was $36.9{ }^{\circ} \mathrm{C}$ (Interquartile range, $36.7-37.2{ }^{\circ} \mathrm{C}$ ). Of the individuals whose body temperature measure was taken $(\mathrm{n}=7856), 396$ (5.0\%) had fever (axillary temperature $\geq 37.5^{\circ} \mathrm{C}$ ). The largest proportion of those with fever was observed during the dry and cool season of August $2004(\mathrm{n}=130,32.8 \%)$ and dry and hot season of February $2005(\mathrm{n}=117,2935 \%)(\mathrm{p}<0.001)$. The proportion of individuals with fever $\left(\geq 37.5^{\circ} \mathrm{C}\right)$ was significant less in the community from savannah agro-ecosystem (Savannah $=5.6 \%$; Rice-irrigation $=7.4 \% ; \quad$ sugarcane $=8.0 \%$, 
Table 3 Number of individuals screened, mean age, Plasmodium falciparum (Pf) gametocyte rate, parasite prevalence, spleen rate and geometric mean parasite density (GMPD) by agro-ecosystems and village

\begin{tabular}{|c|c|c|c|c|c|c|c|}
\hline Ecosystem & Village & No. screened & Mean age & $\begin{array}{l}\text { P. falciparum } \\
\text { N (\%) }\end{array}$ & GMPD/ $\mu \mathrm{l}$ & Gametocyte rate & $\begin{array}{l}\text { Spleen rate }{ }^{a} \\
N(\%)\end{array}$ \\
\hline \multirow[t]{3}{*}{ Savannah } & Luhindo & 1087 & 12.01 & $301(27.7)$ & 228.48 & 1.20 & $288(27.1)$ \\
\hline & Dakawa & 995 & 13.50 & $206(20.7)$ & 161.44 & 0.98 & $105(10.6)$ \\
\hline & Total & 2082 & & $507(24.4)$ & & & $393(19.1)$ \\
\hline Sugarcane & Mtibwa & 1201 & 11.71 & $87(7.2)$ & 434.25 & 2.17 & $58(4.8)$ \\
\hline \multirow[t]{5}{*}{ Rice-irrigation } & Mkindo & 1212 & 12.09 & $557(46.0)$ & 204.46 & 4.60 & $199(16.4)$ \\
\hline & Dihombo & 1125 & 13.42 & $349(31.0)$ & 278.64 & 1.73 & $198(17.6)$ \\
\hline & Mbogo & 1142 & 12.78 & $470(41.2)$ & 322.13 & 1.29 & $204(17.9)$ \\
\hline & Komtonga & 1126 & 14.18 & $746(66.3)$ & 257.24 & 1.34 & $330(29.5)$ \\
\hline & Total & 4605 & & $2122(46.1)$ & & & $931(20.3)$ \\
\hline Overall & & 7888 & 12.79 & $2716(34.4)$ & 269.52 & 1.78 & $1382(17.6)$ \\
\hline
\end{tabular}

a Done for children children $\leq 15$ years

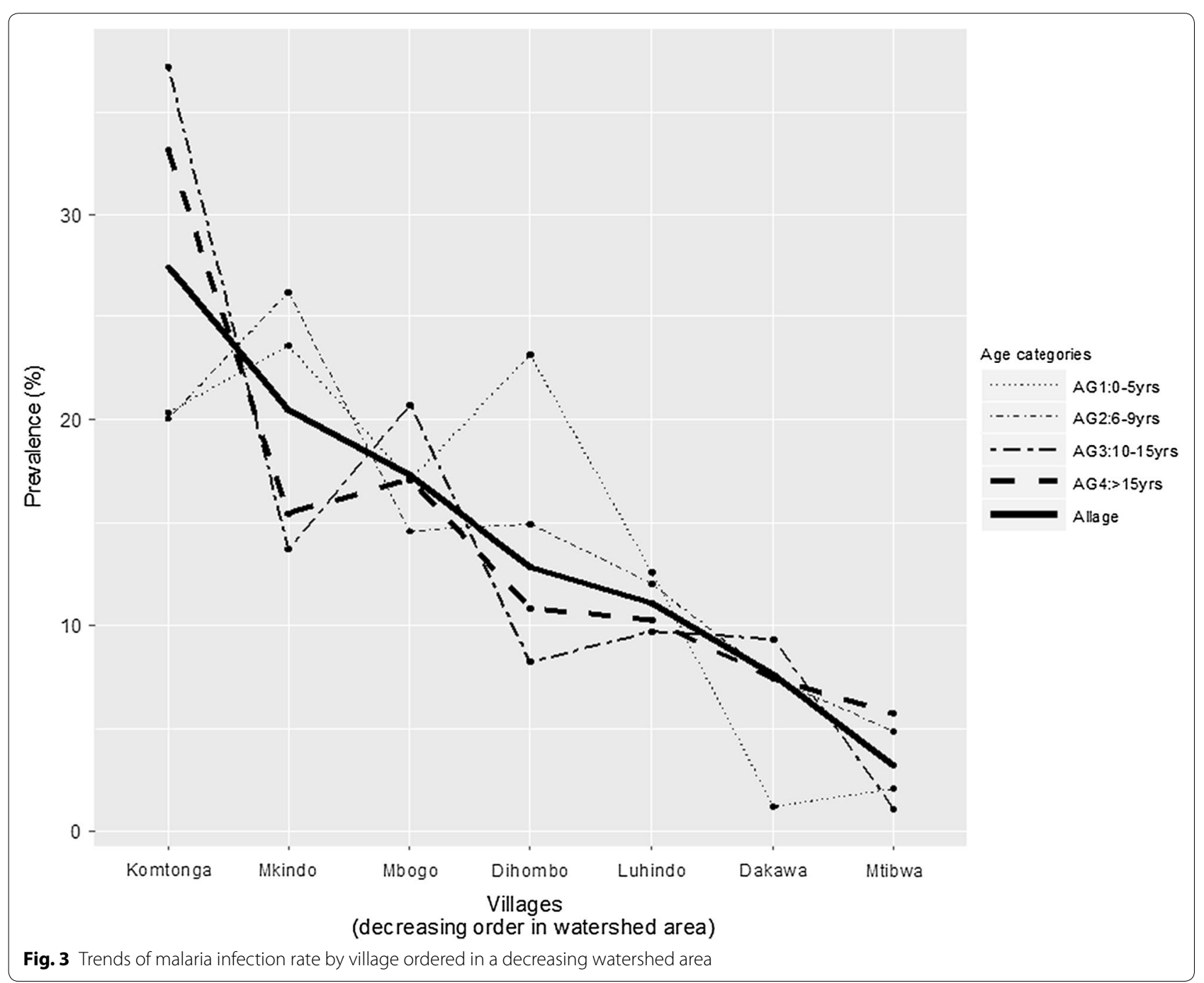


$\mathrm{p}$-value $=0.0719)$, and, a significant proportion $(61 \%)$ was from community living in rice-irrigation ecosystems. Fever was more profound in individuals with malaria (8.3\%) as compared to those who were not infected (6.1\%), p-value $=0.002$.

Enlargement of the spleen among children $\leq 15$ years was observed mostly among individuals living in riceirrigation agro-ecosystem than in the other ecosystems (Table 3). When spleen rate was analysed by age groups, it was observed to vary from $17.4 \%, 19.9 \%, 20.0 \%$ and $5.6 \%$ for $\leq 5$ years, $5-9$ years, $10-15$ years and $>15$ years old, respectively. Spleen enlargement was significantly higher in malaria infected individuals (30.4\%, 95\% CI $28.6-32.2 \%)$ than non-infected $(14.3 \%, 95 \%$ CI $13.3-15.4 \%)$.

The average proportion of gametocytaemic individuals (proportion of those with asexual parasites who also had asexual-stage gametocytes) was $1.8 \%$. It was higher in Mkindo (4.6\%) and lower in Dakawa (0.98\%). It was $1.7 \%$, $2.2 \%, 1.3 \%, 1.2 \%$ and $1.3 \%$ in Dihombo, Mtibwa, Komtonga, Luhindo and Mbogo, respectively (Table 3 ).

Plasmodium falciparum was the dominant parasite species (99.5\%). Mixed infections accounted for $0.5 \%(13 / 2716)$ of the total malaria parasite infections. Mixed infections due to $P$. falciparum + Plasmodium malariae were more common (0.4\%) than due to $P$. falciparum + Plasmodium ovale (0.07\%). Mixed P. falciparum $+P$. malariae infections were observed among persons living in four of the seven study villages. Mixed $P$. falciparum $+P$. ovale infections were only observed among individuals in Dihombo village. One individual from the sugarcane ecosystem was found to be infected with P. malariae (Table 4).

\section{Mosquito net utilization}

On average, over three-quarters (78.9\%; range $=69.7$ $88.5 \%$ ) of the individuals slept under a mosquito net the previous night. The largest mosquito net coverage was in Mtibwa (88.5\%) followed by Mbogo (85.3\%), Dihombo
(80.6\%), Komtonga (80.3\%), Mkindo (75.3\%) and the lowest coverage was in Dakawa (69.7\%). Of the total persons (6200/7893) reported using nets, 635 were $<5$ years, 2831 6-9 years, $181810-15$ years and 940 were $\geq 15$ years of age. However, zooming within these age groups, $<5$ years had the highest proportion $(84.1 \%)$ of those sleeping under mosquito net. The proportions for the other age groups were $79.6 \%, 75.3 \%$ and $80.7 \%$ for $6-9,10-15$ and $>15$ years old, respectively.

\section{Prevalence of anaemia among children}

Overall mean haemoglobin $(\mathrm{Hb})$ level was $10.8 \mathrm{~g} /$ $\mathrm{dl}$ (range $=3.6-15.2 \mathrm{~g} / \mathrm{dl}$ ). The mean $\mathrm{Hb}$ level was similar among female $(10.83 \pm 1.91 \mathrm{~g} / \mathrm{dl})$ and male $(10.86 \pm 1.81 \mathrm{~g} / \mathrm{dl})$ children. On average $47.1 \%$ of the children were anaemic. Anaemia levels were similar between males (45.8\%) and females (47.9\%). Age group most affected by anaemia was $10-15$ years $(49.3 \%)$. Anaemia was more prevalent (60.5\%) among individuals in the savannah than in the rice-irrigation $(48.2 \%)$ or sugarcane farming communities (23\%) (Table 5). However, severe anaemia was more prevalent among children in rice-irrigation village of Mbogo. Anaemia level was significantly higher in malaria infected individuals $(55.2 \%$, 95\% CI $50.2-60.1 \%)$ than non-infected $(41.6 \%$, 95\% CI $37.8-45.4 \%)$. Significant differences in anaemia levels were detected between infected and non-infected individuals in rice-irrigation agro-ecosystem and specifically in Komtonga village.

\section{Determinants of malaria}

Mixed effects logistic regression models were fitted to determine factors associated with malaria infection in the study population. Agro-ecosystems, levels of watershaded area and village variables were highly correlated. Based on the criteria set, the levels of water-shaded area was retained. The variable that distinguish the schoolchildren and general community members was omitted due to high variation initiation factor value.

Table 4 Malaria parasite species composition by agro-ecosystem and village in Mvomero district

\begin{tabular}{|c|c|c|c|c|c|c|}
\hline Ecosystem & Village & $P f$ & $P f+P m$ & $P f+P o$ & $P m$ & Tota \\
\hline \multirow[t]{2}{*}{ Savannah } & Luhindo & $301(100 \%)$ & 0 & 0 & 0 & 301 \\
\hline & Dakawa & 205 (99.5\%) & $1(0.5 \%)$ & 0 & 0 & 206 \\
\hline Sugarcane & Mtibwa & 82 (94.3\%) & $4(4.6 \%)$ & 0 & $1(1.2 \%)$ & 87 \\
\hline \multirow{5}{*}{ Rice-irrigation } & Mkindo & $557(100 \%)$ & 0 & 0 & 0 & 557 \\
\hline & Dihombo & 347 (99.4\%) & 0 & $2(0.6 \%)$ & 0 & 349 \\
\hline & Mbogo & 467 (99.4\%) & $3(0.6 \%)$ & 0 & 0 & 470 \\
\hline & Komtonga & 744 (99.7\%) & $2(0.3 \%)$ & 0 & 0 & 746 \\
\hline & Total & 2703 (99.5\%) & $10(0.4 \%)$ & $2(0.07 \%)$ & $1(0.04 \%)$ & 2716 \\
\hline
\end{tabular}


Table 5 Mean haemoglobin $(\mathrm{Hb})$ level $(\mathrm{g} / \mathrm{dl})$ and the prevalence $(\%)$ of anaemia among children by agro-ecosystems and villages

\begin{tabular}{|c|c|c|c|c|c|c|c|c|}
\hline Ecosystem & Village & Mean $\mathrm{Hb}$ & Range $\mathrm{Hb}$ & Normal ( $\geq 11$ g/dl) & Mild (11.0-10.9/dl) & $\begin{array}{l}\text { Moderate } \\
(7.0-9.9 / \mathrm{dl})\end{array}$ & Severe $(4.0-6.9 / \mathrm{dl})$ & Total \\
\hline \multirow[t]{3}{*}{ Savannah } & Luhindo & 10.4 & $5.8-15.2$ & $60(40.0)$ & $33(22.0)$ & $50(33.3)$ & $7(4.7)$ & 150 \\
\hline & Dakawa & 10.4 & $5.5-13.6$ & $58(38.9)$ & $40(26.9)$ & $44(29.5)$ & $7(4.7)$ & 149 \\
\hline & Total & 10.4 & $5.5-15.2$ & $118(39.5)$ & $73(24.4)$ & $94(31.4)$ & $14(4.7)$ & 299 \\
\hline \multirow[t]{2}{*}{ Sugarcane } & Mtibwa & 11.7 & $4.8-15.2$ & $154(77.0)$ & $31(15.5)$ & $12(6.0)$ & $3(1.5)$ & 200 \\
\hline & Total & 11.7 & $4.8-15.2$ & $154(77.0)$ & $31(15.5)$ & $12(6.0)$ & $3(1.5)$ & 200 \\
\hline \multirow[t]{5}{*}{ Rice-irrigation } & Mkindo & 10.4 & $4.4-14.3$ & $69(45.4)$ & $24(15.8)$ & $49(32.2)$ & $10(6.6)$ & 152 \\
\hline & Dihombo & 11.1 & $4.9-14.9$ & $92(60.9)$ & $31(20.4)$ & $24(15.9)$ & $5(3.3)$ & 152 \\
\hline & Mbogo & 10.5 & $3.6-14.2$ & $47(47.5)$ & $24(23.2)$ & $19(19.2)$ & $10(10.1)$ & 100 \\
\hline & Komtonga & 10.9 & $4.8-14.2$ & $63(52.1)$ & $29(24.0)$ & $26(21.3)$ & $4(3.3)$ & 122 \\
\hline & Total & 10.7 & $3.6-14.2$ & $271(51.8)$ & $108(20.3)$ & $118(22.4)$ & $29(5.5)$ & 526 \\
\hline Overall & Total & 10.8 & $3.6-15.2$ & $543(52.9)$ & $212(20.7)$ & $224(21.8)$ & $46(4.5)$ & 1025 \\
\hline
\end{tabular}

Gender, age, use of mosquito nets, and season of the year were found as significant determinants for $P$. falciparum malaria infection (Table 6). Male individuals had $16 \%$ higher odds of having malaria than females $(\mathrm{OR}=1.16$, 95\% CI 1.05, 1.29). Children 6-9 years had the risk of over $50 \%$ compared to the very young ones $(0-5$ years). The risk for the older children (1015 years) was $24 \%$ higher. These results demonstrated high vulnerability to malaria infection among adolescents. Adults presented an age favour and indicated a less risk (by $68 \%$ ) to get malaria compared to $0-5$ years children $(\mathrm{OR}=0.32,95 \%$ CI $0.25,0.40)$.

Sleeping under a mosquito net reduced the risk of getting malaria by $26 \%$. Season of the year was significantly associated with the rate of infection. Comparing between dry and hot seasons, risk of malaria was highest during dry and cool season $(\mathrm{OR}=1.98,95 \%$ CI 1.71 , 2.3). Living in high water shaded areas increased the chances of getting malaria up to 15 times compared to living in dry shaded areas. Similarly, results obtained in the bivariate analysis also indicated that living in savannah and rice-irrigation areas were significantly increasing the risk of malaria as compared to living in sugarcane plantations. However, geometric mean parasite density was highest among residents of sugarcane ecosystem $(434.25 / \mu \mathrm{l})$ and lowest in the savannah $($ Dakawa $=161.44 / \mu \mathrm{l})$. Trend of the risk by village indicates a high (25 times) and significant odds for malaria infection for individuals living in Komtonga (highly wet shaded) than in Mtibwa (dry shaded). This risk reduced sharply in villages with lesser water shaded area (Fig. 4). The variance of village-specific errors was estimated at 0.13 (95\% CI 0.05-0.4) indicating moderate variance.

\section{Discussion}

In this study, about one-third of individuals in the district were infected with malaria parasites, children aged 6-9 years being the most affected group. A recent crosssectional study among schoolchildren (6-13 years) in a neighbouring Morogoro Urban district in Tanzania by Nzobo et al. [68] reported a relatively lower malaria prevalence of $5.4 \%$, with those aged 6-9 years reported to be the most affected. Unlike in this study where males were at higher risk of malaria, in a study in Morogoro Urban, females were more affected with malaria than males [68]. In a hospital-based study in a western town of Kisumu in Kenya, malaria parasitaemia levels were significantly higher in males than females [69], indicating that males are probably more vulnerable to malaria infection than females. The difference between these findings is likely to be attributed to socio-behavioural factors which differ between rural and urban settings. In all villages, $P$. falciparum was the most important malaria species. Like many other parts of Tanzania, the prevalences of $P$. malariae or P. ovale in this area were low [70].

The prevalence of malaria varied strongly between age groups and the agro-ecosystems. Malaria prevalence was highest among communities in rice-irrigation ecosystem. Similar findings have been reported in Burundi [20], Mali $[71,72]$, Tanzania [22, 73], Cameroon [74] and Sri Lanka [49]. These studies reported that prevalence of malaria was highest in irrigated than in non-irrigated cultivation and this was also associated with large number of malaria mosquitoes. Results from this work indicated significant variation in level of parasitaemia even between different rice-irrigation practices. Malaria prevalence was higher among residents in traditional flooding rice irrigation (Komtonga) than improved rice-irrigation (Mkindo). 
Table 6 Mixed-effects logistic regression model on determinants of malaria infection

\begin{tabular}{|c|c|c|c|c|}
\hline \multirow[t]{2}{*}{ Variable } & \multicolumn{2}{|c|}{ Unadjusted } & \multicolumn{2}{|c|}{ Adjusted } \\
\hline & OR & $(95 \% \mathrm{Cl})$ & OR & $(95 \% \mathrm{Cl})$ \\
\hline \multicolumn{5}{|l|}{ Gender } \\
\hline Male & 1.22 & $(1.11,1.34)^{* * *}$ & 1.16 & $(1.05,1.29)^{* *}$ \\
\hline Female & 1.00 & & 1.00 & \\
\hline \multicolumn{5}{|l|}{ Age category (years) } \\
\hline $0-5$ & 1.00 & & 1.00 & \\
\hline $6-9$ & 1.13 & $(0.96,1.33)$ & 1.5 & $(1.25,1.79)^{* * *}$ \\
\hline $10-15$ & 1.56 & $(1.31,1.85)^{* * *}$ & 1.24 & $(1.03,1.5)^{* *}$ \\
\hline$>15$ & 0.37 & $(0.29,0.46)^{* * *}$ & 0.32 & $(0.25,0.4)^{* * *}$ \\
\hline \multicolumn{5}{|l|}{ Usage of mosquito net } \\
\hline No & 1.00 & & 1.00 & \\
\hline Yes & 0.75 & $(0.67,0.83)^{* * *}$ & 0.74 & $(0.66,0.84)^{* * *}$ \\
\hline \multicolumn{5}{|l|}{ Subject group ${ }^{a}$} \\
\hline Schoolchildren & 2.26 & $(2.02,2.53)^{* * *}$ & & - \\
\hline General community & 1.00 & & 1.00 & \\
\hline \multicolumn{5}{|l|}{ Season (round of survey) } \\
\hline Round 1 (August: dry and cool) & 1.61 & $(1.4,1.84)^{* * *}$ & 1.98 & $(1.71,2.3)^{* * *}$ \\
\hline Round 2 (November: short rains) & 1.71 & $(1.49,1.96)^{* * *}$ & 1.92 & $(1.65,2.24)^{* * *}$ \\
\hline Round 3 (February: dry and hot) & 1.00 & & 1.00 & \\
\hline Round 4 (May: long rains) & 1.56 & $(1.36,1.79)^{* * *}$ & 1.69 & $(1.45,1.96)^{* * *}$ \\
\hline \multicolumn{5}{|l|}{ Village $e^{a}$} \\
\hline Komtonga & 25.14 & $(19.56,32.3)^{* * *}$ & & - \\
\hline Mkindo & 10.89 & $(8.52,13.92)^{* * *}$ & & - \\
\hline Mbogo & 8.96 & $(6.99,11.48)^{* * *}$ & & - \\
\hline Dihombo & 5.76 & $(4.48,7.41)^{* * *}$ & & - \\
\hline Luhindo & 4.9 & $(3.8,6.33)^{* * *}$ & & - \\
\hline Dakawa & 3.34 & $(2.56,4.36)^{* * *}$ & & - \\
\hline Mtibwa & 1.00 & & & \\
\hline \multicolumn{5}{|l|}{ Water shaded area } \\
\hline High & 13.3 & $(10.59,16.71)^{* * *}$ & 15.77 & $(6.66,37.36)^{* * *}$ \\
\hline Medium-Low & 4.66 & $(3.7,5.88)^{* * *}$ & 4.81 & $(2.03,11.4)^{* * *}$ \\
\hline Dry & 1.00 & & 1.00 & \\
\hline \multicolumn{5}{|l|}{ Ecosystem $^{a}$} \\
\hline Savannah & 10.94 & $(8.73,13.71)^{* * *}$ & 1.00 & - \\
\hline Rice-irrigation & 4.12 & $(3.24,5.24)^{* * *}$ & & - \\
\hline Sugarcane & 1.00 & & 1.00 & - \\
\hline
\end{tabular}

*** $\mathrm{p}<0.001,{ }^{* *} \mathrm{p}<0.01$

${ }^{a}$ Not included in the multiple regression model due to high correlation or multicollinearity

An entomological survey conducted in the same area indicated variations in mosquito populations where a significant large number of anophelines mosquitoes (particularly An. gambiae) and entomological inoculation rate were observed in areas practicing flooded rice irrigation [34].

Irrigation rice fields are known to provide ideal breeding sites for $A n$. gambiae, the main malaria vector in Africa [21], while An. funestus found commonly in savannah [37]. Irrigated-rice cultivation, depending of the number of cropping cycles, may also extend their breeding season and hence increase the annual duration for malaria transmission [22]. The variations in malaria prevalence within the study district were likely to be due to differences in ecological factors and socio-economic activities which affect malaria transmission risk. Various studies in Tanzania and elsewhere have shown that malaria transmission risk varies even between areas in 


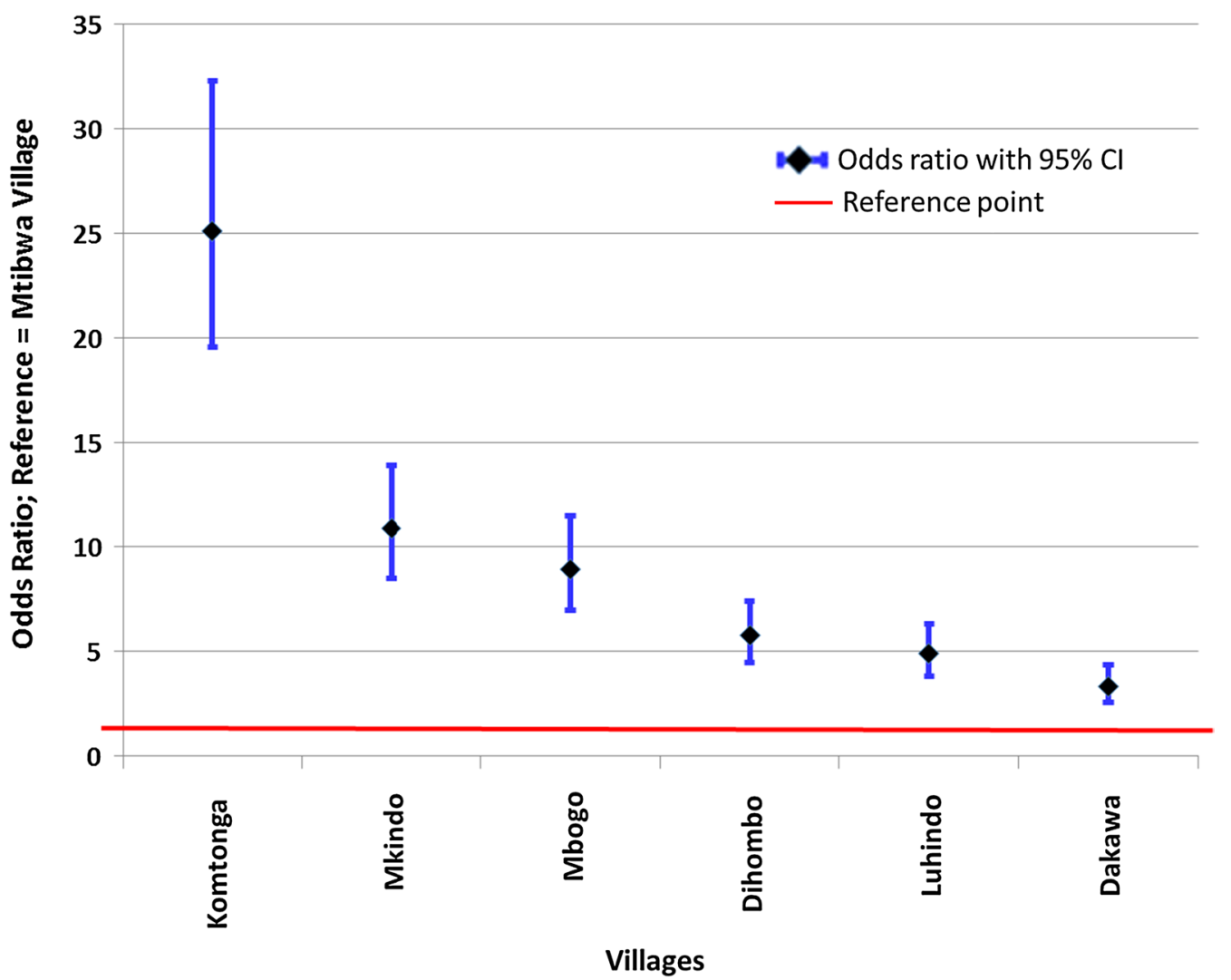

Fig. 4 Trends of risk of malaria by villages arranged in descending order of water shaded area

close proximity [75-77]. Contrary to findings from this study, other studies in East Africa [31, 33] and West Africa [74, 78-80] have reported lower prevalence of malaria among rice-irrigated households than in nonirrigation villages, attributed to improved socio-economic status. Improved socioeconomic status due to rice growing in a study in northern Tanzania [73] was attributed to the reduced malaria prevalence, in spite of increased mosquito populations among villages adjacent to flooded rice fields. This could be explained by the widespread use of interventions by the rice farming community who used the income generated from agricultural production for malaria control, more specific for children [22]. Other factors could be differences in vector species and their feeding practices [32]. These findings emphasize the need for multi-sectoral collaborations while implementing development projects and malaria control strategies, for instance understanding transmission patterns, vector population and population behaviours [81].

In this study, communities living in sugarcane ecosystem had the lowest malaria parasitaemia. Only a few incidence of increase in malaria has been associated with sugarcane in Africa. It is known that a properly maintained sugarcane irrigation system does not offer appropriate breeding sites for malaria vectors [82]. Usually, sugarcane irrigation does not support large expanses of water surfaces. Moreover, under normal conditions, the thick vegetation cover created by sugarcane growth would limit the numbers of An. gambiae because of this species preference for open breeding sites [34].

This study included school-children tested for malaria while at school. As there were no restrictions in registration of students, it is possible, though less likely, that some children were included in estimation of malaria prevalence in village different to where they actually reside, which could influence prevalence levels observed.

This study demonstrated that about half of the children involved were anaemic. The findings show that moderate anaemia was common in children in all villages. Children in the sugarcane plantation had the lowest prevalence of anaemia than those in other agro-ecosystems. Like in Mvomero district, anaemia is a major health problem in Tanzania, especially among young children. However, a similar study in a neighbouring district of Morogoro Urban, reported a relatively lower anaemia prevalence of $10.1 \%$ [68]. The findings that the prevalence of anaemia among children in the savannah ecosystems was higher than in 
irrigation ecosystem (with higher malaria prevalence) suggest that anaemia in this area is most likely to be the result of dietary deficiency. Population based studies in Tanzania have indicated that the most common cause of anaemia among children in Tanzania is nutritional anaemia [83]. Communities in Dakawa and Luhindo are pastoralists and agro-pastoralists with a significant number working in large rice farms. This livelihood had been associated with unstable income and poor family care practices where either women are left home with less income while men moving with animals or children left on their own while both parents working out. Most families in the sugarcane plantation agro-ecosystem work in the factory where stable income and probably more time to provide childcare could be the case. The findings of the current study are similar to the national figures of anaemia in Tanzania where almost three quarters of the children were reported anaemic; $25 \%$ with mild anaemia, $43 \%$ with moderate anaemia, and $4 \%$ with severe anaemia in 2012 [83]. However the situation has significantly improved as reported by a recent survey of 2016 [9]. On the other hand, enlargement of spleen was high in a Savannah village with low malaria infection rate which might indicate delays in care seeking for malaria treatment $[84,85]$.

High water shed was associated with higher malaria prevalence in this study. High water sheds provide conditions such as vegetation cover, temperature, and humidity conditions that are conducive to distribution and survival of malaria vectors. The fact that Komtonga village is characterized by flooding water almost throughout the year, provide suitable mosquito breeding habitats [34] and hence community is at higher risk of malaria infection than those with fewer/less water shaded conditions.

\section{Conclusions}

There are significant variations in malaria parasitaemia prevalence among individuals living in different agroecological zones within small geographical localities. Such variations are likely to be attributed to different transmission levels and socio-economic factors. The variability of the levels of parasitaemia illustrates the existing of different micro-ecological zones, hence the spatial and temporal variation in malaria transmission. It is therefore important, that malaria control/elimination strategies are designed to focus on specific local needs and those who practice irrigation agriculture need to be well informed of the consequences of their farming practices. National and sub-national malaria control programmes need to allocate resources for malaria control proportionate to risk of malaria transmission in specific localities.

\section{Abbreviations}

AIC: Akaike information criteria; Cl: confidence interval; GMPD: geometric mean parasite density; Hb: haemoglobin; ITN: insecticide-treated nets; IQR: interquartile range; NIMR: National Institute for Medical Research; OR: odds ratio; TDHS-MIS: Tanzania Demographic and Health Survey and Malaria Indicator Survey; VIF: variance inflation factor; WHO: World Health Organization.

\section{Acknowledgements}

We are grateful to Mr. Steven Mkongewa and Ms. Beatrice Shemgunda for their technical assistance. Appreciation to the contribution of the lead statistician of the project, the late Mr. Kesheni Senkoro.

\section{Authors' contributions}

SFR, LEGM and EHS were responsible for study design, development of survey tools and fieldwork supervision; SFR lead the data management, analysis, interpretation of findings and draft the initial version of the manuscript. All authors participated in the data collection, provided intellectual and scientific expertise to the manuscript. All authors read and approved the final manuscript.

\section{Funding}

This study received financial assistance from the International Water Management Institute through the Systemwide Initiative in Malaria and Agriculture and the Tanzania Ministry of Health.

\section{Availability of data and materials}

The datasets generated and used for this manuscript are available from the corresponding author on reasonable request.

\section{Ethics approval and consent to participate}

This study received an ethical clearance from the Medical Research Coordinating Committee of the National Institute for Medical Research. Informed consent was obtained from individual adult participants and from parents and caregivers of the children.

\section{Consent for publication}

Not applicable.

\section{Competing interests}

The authors declare that they have no competing interests.

\section{Author details}

${ }^{1}$ National Institute for Medical Research, 3 Barack Obama Drive, P.O. Box 9653, Dar es Salaam, Tanzania. ${ }^{2}$ SACIDS Foundation for One Health, Sokoine University of Agriculture, Chuo Kikuu, P.O. Box 3297, Morogoro, Tanzania.

Received: 14 December 2018 Accepted: 1 July 2019

Published online: 09 July 2019

\section{References}

1. WHO. World Malaria Report 2017. Geneva: World Health Organization; 2017.

2. WHO. World malaria report 2016. Geneva: World Health Organization; 2016.

3. Mabey D, Peeling R, Ustianowski A. Tropical infectious diseases: diagnostics for the developing world. Nat Rev Microbiol. 2004;2:231-40.

4. Snow R, Guerra C, Noor A, Myint H, Hay S. The global distribution of clinical episodes of Plasmodium falciparum malaria. Nature. 2005;434:214-7.

5. Idro R, Aketch S, Gwer S, Newton C. Research priorities in the management of severe Plasmodium falciparum malaria in children. Ann Trop Med Parasitol. 2006;100:95-108.

6. Hagenlocher M, Castro MC, Gething P, Patil A, Smith D, Guerra C, et al. Mapping malaria risk and vulnerability in the United Republic of Tanzania: a spatial explicit model. Popul Health Metr. 2015;13:2.

7. WHO. Haemoglobin concentrations for the diagnosis of anaemia and assessment of severity. Vitamin and mineral nutrition information system. Geneva: World Health Organization; 2011.

8. Winskill P, Rowland M, Mtove G, Malima RC, Kirby MJ. Malaria risk factors in north-east Tanzania. Malar J. 2011;10:98. 
9. TDHS-MIS, Tanzania Demographic and Health Survey and Malaria Indicator Survey. Dar es Salaam, Tanzania and Rockville, Maryland, USA; 2016.

10. Mboera LEG, Rumisha SF, Lyimo EP, Chiduo MG, Mangu CD, Mremi IR, et al. Cause-specific mortality patterns among hospital deaths in Tanzania, 2006-2015. PLoS ONE. 2018;13:e0205833.

11. Korenromp EL, Armstrong-Schellenberg JRM, Williams BG, Nahlen BL, Snow RW. Impact of malaria control on childhood anaemia in Africaa quantitative review. Trop Med Int Health. 2004;9:1050-65.

12. Ronald LA, Kenny SL, Klinkenberg E, Akoto AO, Boakye I, Barnish G, et al. Malaria and anaemia among children in two communities of Kumasi, Ghana: a cross-sectional survey. Malar J. 2006;5:105.

13. Mazigo HD, Rumisha SF, Chiduo MG, Bwana VM, Mboera LEG. Malaria among rice farming communities in Kilangali village, Kilosa district, Central Tanzania: prevalence, intensity and associated factors. Infect Dis Poverty. 2017;6:101.

14. Craig MH, Snow RW, le Sueur D. A climate-based distribution model of malaria transmission in sub-Saharan Africa. Parasitol Today. 1999;15:105-11.

15. Patz JA, Graczyk TK, Geller N, Vittor AY. Effects of environmental change on emerging parasitic diseases. Int J Parasitol. 2000;30:1395-405.

16. Minakawa N, Sonye G, Mogi M, Githeko A, Yan G. The effects of climatic factors on the distribution and abundance of malaria vectors in Kenya. J Med Entomol. 2002;39:833-41.

17. Adu-Prah S, Kofi Tetteh E. Spatiotemporal analysis of climate variability impacts on malaria prevalence in Ghana. Appl Geogr. 2015;60:266-73.

18. Chirebvu E, Chimbari MJ, Ngwenya BN, Sartorius B. Clinical malaria transmission trends and its association with climatic variables in Tubu village, Botswana: a retrospective analysis. PLOS ONE. 2016;11:e0139843.

19. Hunter JM, Rey L, Scott D. Man-made lakes and man-made diseases. Towards a policy resolution. Soc Sci Med. 1982;16:1127-45.

20. Coosemans M. Comparison of malarial endemicity in a rice-growing zone and in a cotton-growing zone in the Rusizi Plain, Burundi. Ann Soc Belg Med Trop. 1985;65(Suppl 2):187-200.

21. Carnevale P, Guillet P, Robert $V$, Fontenille D. Diversity of malaria in rice growing areas of the Afrotropical region. Parassitologia. 1999;41:273-6.

22. Ijumba J, Lindsay S. Impact of irrigation on malaria in Africa: paddies paradox. Med Vet Entomol. 2001;15:1-11.

23. Worrall E, Basu S, Hanson K. The relationship between socio-economic status and malaria: a review of the literature. Trop Med Int Health. 2005; 10:1047-59.

24. Keiser J, De Castro MC, Maltese MF, Bos R, Tanner M, Singer BH, et al. Effect of irrigation and large dams on the burden of malaria on a global and regional scale. Am J Trop Med Hyg. 2005;72:392-406.

25. Baragatti M, Fournet F, Henry M-C, Assi S, Ouedraogo H, Rogier C, et al. Social and environmental malaria risk factors in urban areas of Ouagadougou, Burkina Faso. Malar J. 2009;8:13.

26. Deressa W, Ali A, Berhane Y. Review of the interplay between population dynamics and malaria transmission in Ethiopia. Ethiop J Health Dev. 2006;20:137-44

27. Hawkes C, Ruel M. The links between agriculture and health: an intersectoral opportunity to improve the health and livelihoods of the poor. Bull World Health Organ. 2006;84:984-90.

28. Yasuoka J, Levins R. Impact of deforestation and agricultural development on anopheline ecology and malaria epidemiology. Am J Trop Med Hyg. 2007;76:450-60

29. Randell H, Dickinson K, Shayo E, Mboera L. Environmental management for malaria control: knowledge and practices in Mvomero, Tanzania. Ecohealth. 2010;7:507-16.

30. Kebede A, McCann JC, Kiszewski AE, Ye-Ebiyo Y. New evidence of the effects of agro-ecologic change on malaria transmission. Am J Trop Med Hyg. 2005;73:676-80.

31. Mutero CM, McCartney M, Boelee E. Agriculture, malaria and water-associated diseases: understanding the links between agriculture and health. Washington, DC: International Food Policy Research Institute; 2006.

32. Mutero CM, Kabutha C, Kimani V, Kabuage L, Gitau G, Ssennyonga J, et al. A transdisciplinary perspective on the links between malaria and agroecosystems in Kenya. Acta Trop. 2004;89:171-86.
33. Ijumba JN, Mosha FW, Lindsay SW. Malaria transmission risk variations derived from different agricultural practices in an irrigated area of northern Tanzania. Med Vet Entomol. 2002;16:28-38.

34. Mboera LEG, Senkoro KP, Mayala BK, Rumisha SF, Rwegoshora RT, Mlozi MRS, et al. Spatio-temporal variation in malaria transmission intensity in five agro-ecosystems in Mvomero district, Tanzania. Geospat Health. 2010;4:167.

35. Muturi EJ, Mwangangi J, Shililu J, Muriu S, Jacob B, Kabiru E, et al. Mosquito species succession and physicochemical factors affecting their abundance in rice fields in Mwea, Kenya. J Med Entomol. 2007:44:336-44.

36. Diuk-Wasser MA, Touré MB, Dolo G, Bagayoko M, Sogoba N, Sissoko I, et al. Effect of rice cultivation patterns on malaria vector abundance in rice-growing villages in Mali. Am J Trop Med Hyg. 2007;76:869-74.

37. Cohuet A, Simard F, Wondji CS, Antonio-Nkondjio C, Awono-Ambene P, Fontenille D. High malaria transmission intensity due to Anopheles funestus (Diptera: Culicidae) in a village of savannah-forest transition area in Cameroon. J Med Entomol. 2004;41:901-5.

38. Oomen JMV, de Wold J, Jobin WR. Health and irrigation: incorporation of disease control measures in irrigation: a multi-faceted task in design, construction and operations. Nairobi: ILRl; 1988.

39. Norris DE. Mosquito-borne diseases as a consequence of land use change. EcoHealth. 2004;1:19-24.

40. Patz JA, Daszak P, Tabor GM, Aguirre AA, Pearl M, Epstein J, et al. Unhealthy landscapes: policy recommendations on land use change and infectious disease emergence. Environ Health Perspect. 2004;112:1092-8.

41. Stevenson JC, Stresman GH, Gitonga CW, Gillig J, Owaga C, Marube E, et al. Reliability of school surveys in estimating geographic variation in malaria transmission in the Western Kenyan highlands. PLOS ONE. 2013;8:e77641.

42. World Bank Group. Tanzania Mainland Poverty Assessment. 2015.

43. Shikuku KM, Winowiecki L, Twyman J, Eitzinger A, Perez JG, Mwongera C, et al. Smallholder farmers' attitudes and determinants of adaptation to climate risks in East Africa. Clim Risk Manag. 2017;16:234-45.

44. Menozzi D, Fioravanzi M, Donati M. Farmer's motivation to adopt sustainable agricultural practices. Bio-based Appl Econ. 2015;4:125-47.

45. Kibret S, Alemu Y, Boelee E, Tekie H, Alemu D, Petros B. The impact of a small-scale irrigation scheme on malaria transmission in Ziway area, Central Ethiopia. Trop Med Int Health. 2009;15:41-50.

46. Wielgosz B, Kato E, Ringler C. Agro-ecology, household economics and malaria in Uganda: empirical correlations between agricultural and health outcomes. Malar J. 2014;13:251.

47. Jaleta K, Hill S, Seyoum E. Agro-ecosystems impact malaria prevalence: large-scale irrigation drives vector population in western Ethiopia. Malar J. 2013;12:350.

48. Mboera L, Mazigo HD, Rumisha S, Kramer R. Towards malaria elimination and its implication for vector control, disease management and livelihoods in Tanzania. MalarWorld J. 2013:4:19.

49. Klinkenberg E, van der Hoek W, Amerasinghe FP. A malaria risk analysis in an irrigated area in Sri Lanka. Acta Trop. 2004;89:215-25.

50. Klinkenberg E, McCall PJ, Hastings IM, Wilson MD, Amerasinghe FP, Donnelly MJ. Malaria and irrigated crops, Accra, Ghana. Emerg Infect Dis. 2005;11:1290-3.

51. Mboera LEG, Senkoro KP, Rumisha SF, Mayala BK, Shayo EH, Mlozi MRS. Plasmodium falciparum and helminth coinfections among schoolchildren in relation to agro-ecosystems in Mvomero district, Tanzania. Acta Trop. 2011;120:95-102

52. Asenso-Okyere K, Asante F, Tarekegn J, Andam K. The linkages between agriculture and malaria: issues for policy, research, and capacity strengthening. Washington DC: International Food Policy Research Institute; 2009.

53. Gebreslasie MT. A review of spatial technologies with applications for malaria transmission modelling and control in Africa. Geospat Health. 2015;10:328.

54. National Bureau of Statistics Ministry of Finance. United Republic of Tanzania. Dar es Salaam: Population and Housing Census; 2013.

55. Daniel W. Biostatistics: a foundation for analysis in the health sciences. 7th ed. New York: Wiley; 1999.

56. Lwanga S, Lemeshow S. Sample size determination in health studies: a practical manual. 1991.

57. Naing $L$, Winn T, Rusli BN. Practical issues in calculating the sample size for prevalence studies. Arch Orofac Sci. 2006:1:9-14 
58. Lemnge MM, Msangeni HA, Rønn AM, Salum FM, Jakobsen PH, Mhina $\mathrm{Jl}$, et al. Maloprim malaria prophylaxis in children living in a holoendemic village in north-eastern Tanzania. Trans R Soc Trop Med Hyg. 1997;91:68-73.

59. Kazadi W, Sexton JD, Bigonsa M, W'Okanga B, Way M. Malaria in primary school children and infants in kinshasa, democratic republic of the congo: surveys from the 1980s and 2000. Am J Trop Med Hyg. 2004;71:97-102.

60. Deloron P, Ringwald P, Luty AJ, Renaut A, Minh TN, Mbessy JR, et al. Relationships between malaria prevalence and malaria-related morbidity in school children from two villages in central Africa. Am J Trop Med Hyg. 1999;61:99-102.

61. Ekpenyong EA, Eyo JE. Malaria control and treatment strategies among school children in semi-urban tropical communities. West Indian Med J. 2008:57:456-61.

62. Kapesa A, Kweka EJ, Zhou G, Atieli HE, Kamugisha E, Mazigo HD, et al. Utility of passive malaria surveillance in hospitals as a surrogate to community infection transmission dynamics in western Kenya. Arch Public Health. 2018;76:39.

63. Mboera L, Shayo E, Senkoro K, Rumisha S, Mlozi MR, Mayala BK. Knowledge, perceptions and practices of farming communities on linkages between malaria and agriculture in Mvomero district, Tanzania. Acta Trop. 2010;113:139-44.

64. Gilles H, Warrell D. Bruce-Chwatt's essential malariology. London: Edward Arnold; 1993

65. Cuzick J. A Wilcoxon-type test for trend. Stat Med. 1985;4:87-90.

66. Akaike H. Information theory and an extension of the maximum likelihood principle. Breakthrough in Statistics. 1992;1:610-24.

67. Farrar D, Glauber R. Multicollinearity in regression analysis: the problem revisited. Rev Econ Stat. 1967;49:92-107.

68. Nzobo BJ, Ngasala BE, Kihamia CM. Prevalence of asymptomatic malaria infection and use of different malaria control measures among primary school children in Morogoro Municipality, Tanzania. Malar J. 2015;14:491.

69. Ng'ong'a G, Sharma R, Gicheru M, Odour M, Vulule J. Influence of age and sex on Plasmodium falciparum malaria susceptibility in children 1-10 year in Kisumu Town, Kenya. Kenyatta University Repository. 2011.

70. Mboera LEG. Fifty years of health research in Tanzania (1949-1999). Annotated Bibliography. DUP (1996) Ltd; 2000.

71. Klinkenberg E, Takken W, Huibers F, Touré YT. The phenology of malaria mosquitoes in irrigated rice fields in Mali. Acta Trop. 2003;85:71-82.

72. Sogoba N, Doumbia S, Vounatsou P, Bagayoko MM, Dolo G, Traoré SF, et al. Malaria transmission dynamics in Niono, Mali: the effect of the irrigation systems. Acta Trop. 2007;101:232-40.
73. Ijumba JN, Shenton FC, Clarke SE, Mosha FW, Lindsay SW. Irrigated crop production is associated with less malaria than traditional agricultural practices in Tanzania. Trans R Soc Trop Med Hyg. 2002;96:476-80.

74. Audibert M, Josseran R, Josse R, Adjidji A. Irrigation, schistosomiasis, and malaria in the Logone Valley, Cameroon. Am J Trop Med Hyg. 1990;42:550-60.

75. Yé Y, Kyobutungi C, Louis VR, Sauerborn R. Micro-epidemiology of Plasmodium falciparum malaria: is there any difference in transmission risk between neighbouring villages? Malar J. 2007;6:46.

76. Wang S-J, Lengeler C, Mtasiwa D, Mshana T, Manane L, Maro G, et al. Rapid Urban Malaria Appraisal (RUMA) II: epidemiology of urban malaria in Dar es Salaam (Tanzania). Malar J. 2006;5:28.

77. Wang S-J, Lengeler C, Smith TA, Vounatsou P, Cissé G, Diallo DA, et al. Rapid urban malaria appraisal (RUMA) in sub-Saharan Africa. Malar J. 2005;4:40.

78. Faye O, Fontenille D, Gaye O, Sy N, Molez JF, Konate L, et al. Malaria and rice growing in the Senegal River delta (Senegal). Ann Soc Belg Med Trop. 1995;75:179-89.

79. Lindsay S, Wilkins H, Zieler H, Daly R. Ability of Anopheles gambiae mosquitoes to transmit malaria during the dry and wet seasons in an area of irrigated rice cultivation in The Gambia. J Trop Med Hyg. 1991;94:313-24.

80. Sissoko MS, Dicko A, Briët OJT, Sissoko M, Sagara I, Keita HD, et al. Malaria incidence in relation to rice cultivation in the irrigated Sahel of Mali. Acta Trop. 2004;89:161-70.

81. Sanchez-Ribas J, Parra-Henao G, Guimarães AÉ. Impact of dams and irrigation schemes in Anopheline (Diptera: Culicidae) bionomics and malaria epidemiology. Rev Inst Med Trop Sao Paulo. 2012;54:179-91.

82. Packard R. Agricultural development, migrant labor and the resurgence of malaria in Swaziland. Soc Sci Med. 1986;22:861-7.

83. TDHS, Tanzania Demographic and Health Survey. Dar es Salaam, United Republic of Tanzania; 2005.

84. Ozsoy MF, Oncul O, Pekkafali Z, Pahsa A, Yenen OS. Splenic complications in malaria: report of two cases from Turkey. J Med Microbiol. 2004;53:1255-8.

85. Zingman BS, Viner BL. Splenic complications in malaria: case report and review. Clin Infect Dis. 1993;16:223-32.

\section{Publisher's Note}

Springer Nature remains neutral with regard to jurisdictional claims in published maps and institutional affiliations.
Ready to submit your research? Choose BMC and benefit from:

- fast, convenient online submission

- thorough peer review by experienced researchers in your field

- rapid publication on acceptance

- support for research data, including large and complex data types

- gold Open Access which fosters wider collaboration and increased citations

- maximum visibility for your research: over 100M website views per year

At BMC, research is always in progress.

Learn more biomedcentral.com/submissions 